\title{
Factors that influence digital preservation sustainability in academic libraries in South Africa
}

\author{
Tlou Maggie Masenya ${ }^{1}$ and Patrick Ngulube ${ }^{2}$ \\ tm.masenya@webmail.co.za ORCID: 0000-0001-5400-0549 \\ ngulup@unisa.ac.za ORCID: 0000-0002-7676-3931
}

\begin{abstract}
Received: 2 December 2019
Accepted: 25 May 2020

This study investigated the factors that can inform the implementation of sustainable digital preservation in academic libraries, with a view to developing a conceptual preservation model applicable to these institutions. The survey research design was used, underpinned by a quantitative research method and guided by a conceptual framework. Online survey questionnaires were emailed to all twenty-seven academic libraries in South Africa. The findings show that academic libraries in South Africa are significantly affected by the changes in the digital environment. Most of these institutions are faced with many challenges as they attempt to preserve their digital content, including a lack of institutional commitment and involvement; absence of established digital preservation standards, policies and procedures; inadequate resources; lack of skills and training; lack of funding; limited collaboration efforts and partnerships; and technological obsolescence. This study recommends that these institutions can address many of their digital preservation challenges if they leverage these factors. The study proposes a conceptual model for preservation of digital resources in academic libraries, mapped with the Open Archival Information System (OAIS) reference model.
\end{abstract}

Keywords: Digitisation, digital preservation, digital resources, academic library, preservation, sustainability

\section{Introduction}

The increasing application of digital technologies has transformed the modern library into a virtual library. Raju (2014) noted that the proliferation of social media and the explosive growth of digital devices and related applications have collectively altered the traditional academic library beyond recognition. These dramatic changes have led to the creation of electronic resources within academic libraries in South Africa with the result that an enormous amount of information is now available in electronic format, including institutional books, journal articles, manuscripts, theses, dissertations and other library materials. The number of digital resources generated through digitisation of analogue materials has increased during the past decade. Digitisation of analogue material can be used to create surrogates for rare or fragile originals as well as to improve access to and longevity of other resources (Van Deventer \& Pienaar 2008). Lampert and Vaughan (2009) defined digitisation as the process of converting analogue materials to machine-readable formats for the purpose of providing electronic access and preservation to these materials. The goal of any digital preservation system is that the information it contains remains accessible to users over a long period of time (Rosenthal et al. 2005). Academic libraries are, however, running a risk of losing vital digital information due to technology obsolescence, lack of policies and procedures, inadequate resources, and fragile storage media. There are numerous examples of digital data loss. For instance, the American National Aeronautics and Space Administration lost track of Martian experiments done in 1976 as the original data was stored on technology that is now old and inaccessible (NASA-NSSDC 2010). Another example is the Newham Museum Archaelogical Service in the United Kingdom that, as noted by Simpson (2004), lost ten years of fieldwork on about 230 floppy disks containing over 6,000 files due to technology obsolescence. The files were in a variety of proprietary formats which are now archaic and some of digital materials stored in these files have become inaccessible. Digital information is at great risk of loss if digital preservation is not considered and prioritised. Academic institutions in South Africa have recognised a need to prirotise long-term preservation of their fast growing digital collections

Digital preservation aims to ensure protection of information of enduring value for access by present and future generations. Hedstrom (1997: 190) defined digital preservation as the "planning, resource allocation, and application of preservation methods and technologies necessary to ensure that digital information of continuing value remains accessible and usable". On the other hand, the American Library Association (2007) defines digital preservation as a combination of

1. Tlou Maggie Masenya is Senior Lecturer in the Department of Library and Information Studies, Durban University of Technology, South Africa

2. Patrick Ngulube is Professor of Interdisciplinary Research and Postgraduate Studies, University of South Africa 
policies, strategies and actions to ensure that digital objects remain authentic and accessible to users and systems over a long period of time, regardless of the challenges of component and management failures, natural disasters or attacks. For the purpose of this study, digital preservation is perceived as a combination of plans, strategies, actions, policies, procedures, resource allocation, preservation methods and technologies aimed at prolonging the existence of and access to digital objects for as long as necessary by maintaining it either in its original format or in a more persistent format, while protecting its authenticity (Hedstrom 1997, Das, Sharma \& Gurey 2009). Ensuring long-term access to large and everexpanding collections of digital resources has remained a challenge for libraries, archives, museums and research institutions the world over (Corrado \& Moulaison 2014). Digital resources are fragile items that require special care to keep them usable. Unfortunately, in various institutions vast amounts of born-digital data are stored in a digital environment that is unstable. Academic libraries are facing numerous challenges as they attempt to preserve their digital resources, including dealing with rapid obsolescence of the technology used, making accessible mass quantities of digital data, and maintaining trusted repositories that hold documentary evidence of scholarship (Council of Canadian Academies 2015).

Bishoff and Smith (2015) identified lack of funding, lack of expertise, lack of institutional support and uncertainty of where to start as the barriers to implementation of sustainable digital preservation programmes. Sustainable digital preservation is meant to ensure the continuity of digital resources over a required period of time and working within resource limitations. In digital preservation terms, Corrado and Moulaison (2014: 319) described economic sustainability as "a set of business, social, technological, and policy mechanisms that encourage the gathering of important information assets ... [that] support the indefinite persistence of digital preservation systems, enabling access to and use of information assets into the long-term future". According to Corrado and Moulaison (2014) digital preservation sustainability encompasses a range of issues and concerns that contribute to the longevity of digital information and concentrates more on building an infrastructure and approach that is flexible with an emphasis on interoperability and incorporates activities that will facilitate access and availability in the future. Academic libraries thus require a commitment to long-term sustainability of their digital resources in order to address preservation challenges that they are facing. Some of the challenges for digital preservation, as noted by McGovern and McKay (2008), include little control over what is ingested into institutional repositories, deposit of materials in less-than-optimal formats with poor metadata and insufficient intellectual property rights clearance, and digital content that is difficult or costly to preserve. As noted by Anyaoku, Echedom and Baro (2019), digital preservation is also constrained by the absence of established standards, protocols and proven methods for preserving digital information. All these challenges associated with preserving digital assets underscore the need for best practices in ensuring long-term preservation of the increasing number of digital collections within academic libraries. This study investigated the factors that influence digital preservation sustainability in academic libraries in South Africa in order to address these challenges in some part.

\section{Statement of the problem}

The move to a digital world has raised serious and pressing issues on how to organise, access and preserve digital materials for perpetuity, particularly in academic libraries. Being digital does not necessarily mean being continuously accessible. It has been noted that academic libraries risk losing vital digital information if digital preservation is not prioritised and urgent measures taken to rescue deteriorating conditions of materials. As observed by Sigauke and Nengomasha (2012), academic libraries have been grappling with how to manage and preserve their digital output. Some digitised materials have been lost while some remain inaccessible due to the original software being outdated and incompatible with modern operating systems. Electronic documents may be inaccessible just a few years after they were created due to the rapid rate of technological change as content may not be accessible using newer software. As a result, scientists and publishers in many countries are facing problems with accessing research and gaining visibility for their own publications as they and others are unable to decode the formats in which documents have been saved.

The studies undertaken by Sigauke and Nengomasha (2012) and Ngulube (2012) underscore the enormous challenges with which most organisations in African countries are confronted when it comes to the preservation of digital resources, despite the efforts that have been put in place to promote digital preservation. The challenges include the lack of staff trained and experienced in the preservation of digital resources; the lack of awareness of digital preservation; poor technological infrastructure and inadequate resources to carry out preservation practices; lack of policies, standards and procedures to regulate the creation, storage, retrieval and preservation of digital information resources; and poor collaboration efforts and partnerships. All these challenges emphasise the need for digital preservation.

Digital preservation aims at ensuring that digital content remains accessible to user communities for a long period of time and for future generations. Considerable efforts have been made over the past few years to ensure that academic libraries in South Africa are able to access the growing number of digital resources in the future. Many initiatives were aimed at creating collaborative efforts in preservation of digital resources, providing the necessary infrastructure and strengthening 
capacity for safeguarding digital resources in academic libraries in African countries. Unfortunately, it seems, however, that there is no best way to achieve this aim, nor is there an agreement on long-term solutions.

What should academic libraries in South Africa be doing to ensure long-term preservation of their digital resources? Of all the preservation challenges facing academic libraries, none is more pressing than developing workable solutions for digital preservation. These preservation challenges have led to the need to establish factors that constitute a sustainable system to manage and preserve digital resources. An understanding of these factors may assist academic libraries to develop multiple-option, multiple-path strategies to achieve future goals and to progress in effective digital preservation. New models, theories and frameworks are needed to cope with digital preservation challenges (Quisbert 2008). This study thus proposes a conceptual digital preservation model applicable to academic libraries.

\section{Conceptual framework}

The study required the use of different theories and models in order to develop a preservation model applicable to academic libraries in South Africa. The first step in conducting this study was to review various theories and models, with specific reference to the identification of key concepts or elements that constitute a preservation model applicable to South African academic libraries. The study therefore adopted a conceptual framework. A conceptual framework may be defined as "an end result of bringing together a number of related concepts to explain or predict a given event, or give a broader understanding of the phenomenon of interest - or simply of a research problem" (Imenda 2014: 189). According to Ngulube (2019: 9), a conceptual framework "is inductively developed by the researcher through pulling together various components of theories, various concepts embedded in the extant literature, diverse theories, sources and experiences". In ascertaining the best models and theories for effective digital preservation it was found that Davies' (2000) policy, strategy and resources (PSR) troika model, Corrado and Moulaison's (2014) Digital Preservation Triad, and the Digital Preservation Capability Maturity (DPCM) model by Carnegie Mellon University (1990), mapped with the functional requirements of the Open Archival Information System (OAIS) model (Research Libraries Group and OCLC 2002), were appropriate for the current study as they identified the elements contributing to sustainable digital preservation. These preservation theories and models are reviewed and discussed in the next sections.

\subsection{Policy, strategy and resources (PSR) troika model}

Academic institutions are challenged by new digital technologies and, in order not to lose their digital information forever, they need to design and contextualise strategies and policies to preserve effectively their digital resources. The study used Davies' (2000) PSR troika model to understand the key elements that contribute to sustainable digital preservation. This model considers the development of policies, implementation of strategies and adequate resource allocation as key aspects to enable effective preservation of digital resources in academic libraries. Davies (2000) emphasised that any effective understanding of strategy development and contextualisation revolves around an understanding of policies and resources in that organisation. Parsons (1995: 13) defines a policy as "the manifestation of considered judgment, plan, action, tactics and strategy adopted by a government or an organisation". Policy prioritises the planned course of actions adopted and pursued by an organisation or a government (Anyaoku, Echedom \& Baro 2019).

Dressler (2017) stated that an institution can have a meaningful, intelligent policy but ,without the strategy and action to support endeavours, the policy is merely a document with no actionable function. Strategy refers to the plan of how goals will be achieved, and it is articulated by policy; without resources, strategy cannot be implemented (Davies 2000). The essence of a strategy is to provide a plan that employs multiple inputs, options and outputs to achieve policy goals and objectives. The strategies for preserving digital content and the decisions about what content requires short, medium or long-term preservation should be driven by preservation policies (Anyaoku, Echedom \& Baro 2019). Resources refer to the materials, knowledge, skills and capabilities that are available to provide the means to support or facilitate the execution of a planned action (Zlotin \& Zusman 2005). According to Davies (2000), resources are needed to make strategies effective in order for strategies to contribute to the achievement of goals set by policy. The PSR troika model (Davies 2000) was therefore able to assist in understanding the issues surrounding the enactment of preservation policies, the basic principles of strategy development, and the allocation of resources to sustain digital preservation programmes.

\subsection{Digital Preservation Triad}

Corrado and Moulaison (2014) identified three further aspects that constitute sustainable digital preservation: managementrelated activities, technological-related activities and content-centred activities. Corrado and Moulaison's (2014) Digital Preservation Triad includes content because the authors believe that content is the core to digital preservation; without content there is nothing to preserve - no matter how well considered your management, how good your policy, plans and preservation systems, they are worth nothing without content. Management is at the top of the triad model as it is vital to preservation - without management in the form of resources and policies, there is no impetus to preserve digital objects 
(Corrado \& Moulaison 2014). Management activities include human factors related to staff ability to perform roles in digitisation, while content management activities border on management functions such as organising, categorising and structuring information resources. The technological element entails the implementation of digital preservation systems such as a trustworthy digital repository and metadata systems that must be in place in order to make use of resources and implement policies (Corrado \& Moulaison 2014).

An increasing number of academic institutions are making efforts to preserve their library materials through digitisation and implementation of institutional repositories. However, these efforts are being hampered by lack of policies and planning, as well as limited or complete lack of human, financial and technological resources on the part of the institutions with statutory responsibility for digital preservation. It is therefore clear that the sustainability of digital preservation in academic libraries is influenced by key elements of the Digital Preservation Triad such as management and technology-related activities.

\subsection{Digital Preservation Capability Maturity (DPCM) model}

The Digital Preservation Capability Maturity (DPCM) model was also used in this study as a guide to identify the components of sustainable digital preservation programmes. This model is designed to help identify, protect and provide access to longterm and permanent digital assets and to enable organisations to assess the maturity of their software development process and identify key practices necessary to improve the capability of those processes (Carnegie Mellon University 1990). It is based on the functional specifications of ISO 14721 (2003), the auditing criteria of Trustworthy Repositories Audit \& Certification (TRAC), ISO 16363 (2012) and accepted best practices in operational digital preservation repositories. It organises the digital preservation requirements of the aforementioned ISO standards into fifteen components with metrics to assess maturity. The DPCM model identifies additional elements of digital preservation consisting of three interdependent domains, namely: digital preservation infrastructure (policies, strategies, governance, collaboration, technical expertise and designated community), trustworthy digital preservation repositories, and digital preservation services (electronic records survey, ingest, archival storage, media or device renewal, integrity, security, preservation metadata and access) (Carnegie Mellon University 1990). All these elements are essential to the understanding of factors for successful preservation of digital resources in academic libraries.

\subsection{Open Archival Information System (OAIS) model}

The key objective of this study is to establish the factors that influence digital preservation sustainability in academic libraries by mapping them with international preservation standards such as the Open Archival Information System (OAIS) model. The OAIS model is the most widely used reference in the development of digital libraries, digital archives and digital repositories (Quisbert 2008). The OAIS model was proposed by the Consultative Committee for Space Data Systems (CCSDS) to standardise digital preservation practice and provide a set of recommendations for preservation programme implementation (CCSDS 2002). It has been adopted as an ISO standard for guiding the long-term preservation of digital materials. CCSDS (2002) describes the OAIS model as an archive consisting of an organisation of people and systems that has accepted the responsibility to preserve digital information and make it available for a designated community, over a long period of time. As noted by Hockx-Yu (2006), the OAIS model provides a complete functional and information specification of a repository and establishes mandatory responsibilities that an organisation must discharge in order to operate a digital archive or institutional repository. As suggested by Hockx-Yu (2006), repository managers should apply the OAIS principles which focus on the implementation of open access archives in accordance with the OAIS model. Without proper protection, there is a real risk that digital collections will in future neither be retrieved from old storage media nor be rendered from old file formats. As noted by Styblinski and Huang (2006), ensuring ongoing access requires being up-todate with technology changes, and moving digital objects from obsolete to current file formats, storage media and operating systems. The OAIS model can facilitate the implementation of effective digital preservation in academic libraries because it is a reliable guide to storing information, migrating information to newer technologies or formats and preserving digital resources over a long time. The current study therefore found the model appropriate to use as it facilitates a broader understanding of preservation requirements and access to digital information in the long-term.

\section{Literature review on factors that influence digital preservation sustainability}

The underlying assumption is that academic libraries in South Africa, like any other organisations, may be grappling with the preservation of both paper and electronic resources, hence there is a need to understand the extent of preservation of such resources in order to guarantee access to them for future generations. Many academic libraries are digitising materials which are in danger of being lost in the future, such as old manuscripts, photographs, theses, and other pieces of history. To ensure permanent storage of and access to these digital resources, this study found it appropriate to investigate factors that contribute to the sustainability of digital preservation within academic libraries in South Africa. Literature reviewed 
reveals essential factors which contribute to the sustainability of digital preservation which, among others, are implementation of policies and strategies, proper allocation of resources, legal issues, collaboration and partnerships, technical expertise and institutional support (Corrado \& Moulaison 2014, Council of Canadian Academies 2015).

\subsection{Implementation of relevant policies and strategies}

Wright (2012) stated that any long-term access to digital resources and future benefit to academic libraries may be heavily dependent on digital preservation strategies being in place which are underpinned by relevant policy and procedures. Without the development of policies to ensure the longevity of digital resources, academic libraries cannot be said to be undertaking digital preservation. According to the Institute of Museum and Library Services' survey (Institute of Museum and Library Services 2001), a third of academic libraries are involved in digitisation efforts; however, many of these libraries do not have policies to control the execution of such efforts. The report suggested that libraries implement policies regarding standards for preservation and selection of digitised material. A clearly documented and realistic preservation policy will be a roadmap for achieving long-term access to digital content and reaping future benefits of digital preservation.

There are many digital preservation policies which can provide a framework and practical guidelines for developing an institutional digital preservation policy, including: a digital preservation policy model with two phases: a policy level and implementation level (Beagrie et al. 2008); the Joint Information System Committee (Jisc) Digital Preservation Policies Study that outlines a model with the aim of helping institutions develop appropriate digital preservation policies (Beagrie et al. 2008); the Electronic Resource Preservation and Access Network (ERPANET) policy tool which supports digital preservation within libraries allowing them to establish and shape an institution-specific context for preservation activities (Electronic Resource Preservation and Access Network 2003).

In 2012, Ohio State University Libraries embarked on a year-long process to develop a digital preservation policy framework (Noonan 2014). The purpose of the framework was to formalise the library's continuing commitment to the longterm stewardship, preservation and access to its diverse and extensive range of digital assets. Several studies have revealed that most African countries do not have such policy frameworks (Kanyengo 2006, Luyombya 2010, Gbaje \& Zakari 2013). Policies should be implemented to guide digital preservation processes in academic libraries. Such policies should include: digitisation and preservation policy content development and management; collection disaster plans; statements on open access to digital resources, storage, security and intellectual property; and reference to copyright and metadata policies.

\subsection{Proper allocation of resources}

Appropriate allocation of resources is fundamental for sustainable digital preservation. Hedstrom's (1997) study established that digital preservation is complex and costly and, as a result, digital preservation activities and projects require a substantial resource commitment to sustain them over time. According to Corrado and Moulaison (2014), there needs to be institutional commitment for digital preservation to be successful and this includes ensuring that enough financial resources are available to sustain the initiative. Financial support is one of the most important components of institutional commitment to any project; ensuring sustainable preservation of digital resources requires substantial and ongoing financial commitments over time. However, academic libraries do not have funds available to build and sustain their digital preservation programmes, so funding these initiatives is a challenge (Masenya 2018). Digital preservation activities may include several ongoing costs, including:

- technical infrastructure (storage media, equipment purchases, ongoing maintenance, technological obsolescence monitoring and network connectivity);

- $\quad$ staffing (hiring, general and specialised training);

- financial planning (securing ongoing budget commitments, seeking projects grants); and

- $\quad$ outsourcing (preservation methods undertaken by outside vendors).

Questions, such as who will pay for preservation costs, need to be addressed before the implementation process commences. In South Africa, the funding for preservation applications could come from the government, non-governmental organisations or the private sector. Human factors are related to staff ability to perform roles in digital preservation, however, Masenya (2018) established that there is a lack of knowledge, skills and training in digital preservation among staff in academic libraries. The personnel involved in digital preservation initiatives do not possess the required skills to manage and preserve digital resources. In order to assist staff to develop their skills, management needs to create a combined mentoring, training and development programme. 


\subsection{Legal issues}

The lack of a single international copyright law and the variations in copyright laws from country to country present a big challenge for distribution of digital content (Council of Canadian Academies 2015). Copyright issues should be investigated to ensure that intellectual property rights that are legally required to perform the actions necessary for long-term preservation have been granted (Corrado \& Moulaison 2014). Memory institutions must identify all content that is part of a preservation project as there may be content which may require research to identify and locate copyright holders to obtain required permissions (Council of Canadian Academies 2015). As observed by Muir (2004), memory institutions may be reluctant to preserve these collective works because identifying the copyright owners, locating them, obtaining license agreements and keeping records of each agreement is undoubtedly a resource-intensive process. The Canadian Copyright Act established a fair dealing provision, allowing one to reproduce copyright material without permission for specific purposes such as research, education, review and news reporting (Council of Canadian Academies 2015).

In South Africa, Copyright Act 98 of 1978 provides the limitations and general exceptions regarding protection of copyrighted work for libraries, archives and museums with regard to preservation of digital content and making that information available. Some of the points outlined in the Copyright Amendment Bill (13B of 2017) regarding protection of copyrighted work for memory institutions are that these instiutions may make a copy of any work in its collection for the purposes of back up and preservation; may make copies of publicly accessible websites for the purposes of preservation; and may, without the consent of the author, engage in format migration or conversion of works from ageing or obsolete technologies to new technologies in order to preserve the works and to make the resulting copies accessible.

\subsection{Collaboration and partnerships opportunities}

As mentioned by Dollar and Ashley (2014), an organisation with a mandate to preserve electronic records is well served by maintaining and promoting collaboration among its many stakeholders. As noted by Corrado and Moulaison (2014), libraries, archives and museums use collaboration strategies to assemble groups with necessary expertise to advance digital preservation work and take advantage of resources in the larger library and digital preservation community. A collaborative initiative seeks to leverage financial, human and technical resources, promote stewardship, and exchange knowledge about the current and future state of digital initiatives (Dollar \& Ashley 2014). According to the Council of Canadian Academies (2015), collaboration with private companies and academia may allow memory institutions to become involved in new activities that enhance their visibility and to undertake large projects that they could not resource on their own. The International Federation of Library Associations and Institutions (IFLA) encourages libraries to collaborate with other cultural and scientific heritage institutions to provide rich and diverse digital resources that support education and research, tourism and the creative industries (Swan 2012).

Mannheimer and Cote (2017) emphasised that forming partnerships can help build collective knowledge and maximise combined resources to achieve digital preservation goals. For example, librarians from four North American institutions formed the Digital Preservation Working Group (DPWG) in 2015, a collaboration to increase digital preservation efforts across the state of Montana (Mannheimer \& Cote 2017). The DPWG proposed a five-point plan for creating digital preservation partnerships: cultivate a foundation of knowledge and identify a shared vision; assess the current digital preservation landscape at each institution; advocate for the value of digital preservation activities; implement shared digital preservation services; and sustain group activities and establish structures for ongoing support (Mannheimer \& Cote 2017). According to Mannheimer and Cote (2017), the members of DPWG benefited from shared knowledge and expertise gained during the partnership and by implementing a structured plan and developing a model that can serve as a guide for institutions considering a collaborative approach to digital preservation. Africa, however, faces many challenges when it comes to collaborative digital preservation projects and these include lack of access to high-end equipment, complicated customs processes and limited control over the environment (Ryan 2010).

\subsection{Technical expertise}

A viable digital preservation capability requires organisations to have sufficient expertise in electronic records management and digital preservation to support all of the infrastructure and requisite key processes. As noted by Khan and Bhatti (2017), digital expertise encompasses the ability to manage digital library infrastructure, define policies and standards for digitisation, do cost planning, manage staff, train library users and use digital skills to back up digital content. However, personnel with the appropriate skills, competencies and attitudes are not readily available in many African countries to initiate, implement and sustain digitisation projects. Few librarians have computer science qualifications and, increasingly, information technologists are required to develop, customise and maintain sophisticated library technologies and infrastructure. Ngulube (2004) concurred that African archivists lack expertise and are ill-equipped to train others in electronic preservation and digitisation. 
Raju (2014) noted that the dramatic changes, largely the result of rapidly evolving digital technologies, have impacted significantly on the knowledge and skills requirements for information professionals practicing in an e-environment. As a result, technical expertise is required, which internal or contracted staff may possess or could be provided by a centralised service bureau or by external service providers (Dollar \& Ashley 2014). Literature has revealed that many librarians and archivists are not comfortable with the digital world in which they find themselves (Raju 2014); they are technophobic and struggle being stewards of both print and digital information. Khan and Bhatti (2017) further reported that many librarians do not have adequate knowledge to apply security software, use encryption and decryption techniques to protect data, secure data, and protect access by assigning passwords and back-end control systems for a digital library. Academic library management needs to value and encourage continuous learning and invest heavily in staff development across all areas of the organisation (Lewis 2007).

\subsection{Institutional supporting factors}

Corrado and Moulaison (2014) pointed out that, in order to sustain digital preservation initiatives, it is important to align these initiatives with the organisation's goals and mission. Digital preservationists need to be able to convince management and other decision makers that digital preservation is important to the overall mission of the organisation (Corrado \& Moulaison 2014). One of the keys to management buy-in for sustainable digital preservation is to have a communication plan that clearly describes the benefits of digital preservation to management and other stakeholders of the organisation. According to Corrado and Moulaison (2014), many libraries and other cultural institutions have not been able to make digital preservation a high priority. As noted by Corrado and Moulaison (2014), even well-funded projects may be unsuccessful if digital preservation is not a primary concern at the outset. Firstly, management must recognise the importance and the benefits of digital preservation as that will lead them to prioritise digital preservation initiatives. A study by Masenya (2018) observed that lack of commitment hinders the effective implementation of digital preservation.

Academic institutions thus need to be engaged in communication and outreach programmes to clarify the necessity for digital preservation. Outreach tools may include training events, instructional videos, reports, seminars, workshops and conferences. Management also needs to understand users' needs or interests as well as the preservation requirements of the content, communicate requirements to the development team, communicate the status of their digital preservation to stakeholders, communicate priorities, and monitor and assess preservation tools and services to determine applicability toward meeting users' needs and preservation requirements (Dollar \& Ashley 2014). Furthermore, the Council of Canadian Academies (2015) provides institutional supporting factors that are required for the realisation of digital preservation initiatives and these include: the prioritisation of digital opportunities by senior management; developing new business models for these opportunities; the promotion of standardised and generic information and communications technologies (ICT) infrastructure; creating collaborations and partnerships; managing outsourcing; managing the various copyright issues; and developing human and funding resources .

\section{Methodology}

This study adopted a survey research design, underpinned by quantitative research and guided by a conceptual framework. Pretesting of the survey questionnaire was undertaken with information professionals from the University of South Africa and the University of Pretoria to review and offer their input on the first draft of the questionnaire, and minor changes were subsequently made to the content of the instruments. The questionnaire was distributed by email to twenty-seven academic institutions in South Africa and twenty-two completed questionnaires were returned, giving a return rate of $81.5 \%$. The main reason for this high response rate was because most academic institutions took an interest in the study as they were eager to know their digital preservation status as well as about best practices. Respondents included digital preservation practitioners, digitisation administrators and institutional repository managers within academic libraries as their knowledge and experience in the field were critical to the current study. Data was analysed statistically using the Statistical Package for the Social Sciences (SPSS) to measure and summarise the variables in the study. The study used descriptive statistics such as frequencies, percentages and cross-tabulation to assess digital preservation practices in academic libraries in South Africa.

\section{Findings and discussion}

This section first provides the findings on factors that influence digital preservation sustainability in academic libraries before presenting the conceptual integrated model.

\subsection{Factors that influence digital preservation sustainability in academic libraries}

In order to examine the factors that influence digital preservation sustainability in academic libraries, the respondents were asked to rate factors on a scale ranging from strongly agree to strongly disagree (Table 1). Responses indicated that 
copyright and intellectual property rights are the major influencing factor for digital preservation sustainability in academic libraries followed by the following factors ranked in order of the highest number of responses: implementation of trustworthy digital repository, technical expertise, institutional support, implementation of policies, skilled trained staff and knowledge of preservation tools (all selected by 21 respondents; 95.4\%); effective collaboration with other institutions, participatory community and knowledge of metadata systems both accounted for as well as partnerships with other institutions, adequate resources and good governance (selected by 20; 90.9\%); and implementation of preservation strategies (19; $86.4 \%)$.

Table 1 Factors influencing digital preservation sustainability in academic libraries(N=27)

\begin{tabular}{|c|c|c|c|c|c|}
\hline & $\begin{array}{l}\text { Strongly } \\
\text { Agree }\end{array}$ & Agree & Neutral & Disagree & $\begin{array}{l}\text { Strongly } \\
\text { Disagree }\end{array}$ \\
\hline Institutional support & $13(59.1 \%)$ & $8(36.4 \%)$ & $1(4.5 \%)$ & 0 & 0 \\
\hline Implementation of policies and procedures & $17(77.3 \%)$ & $4(18.2 \%)$ & $1(4.5 \%)$ & 0 & 0 \\
\hline Adequate resources & $13(59.1 \%)$ & $7(31.8 \%)$ & $2(9.1 \%)$ & 0 & 0 \\
\hline Effective collaboration with other institutions & $10(45.4 \%)$ & $10(45.4 \%)$ & $2(9.1 \%)$ & 0 & 0 \\
\hline Implementation of preservation strategies & $10(45.4 \%)$ & $9(40.9 \%)$ & $3(13.6 \%)$ & 0 & 0 \\
\hline Participatory community & $10(45.4 \%)$ & $10(45.4 \%)$ & $2(9.1 \%)$ & 0 & 0 \\
\hline Partnerships with other institutions & $14(63.6 \%)$ & $6(27.3 \%)$ & $2(9.1 \%)$ & 0 & 0 \\
\hline Implementation of trustworthy digital repository & $11(50.0 \%)$ & $10(45.4 \%)$ & $1(4.5 \%)$ & 0 & 0 \\
\hline Good governance & $11(50.0 \%)$ & $9(40.9 \%)$ & $2(9.1 \%)$ & 0 & 0 \\
\hline Copyrights and intellectual property rights & $13(59.1 \%)$ & $9(40.9 \%)$ & 0 & 0 & 0 \\
\hline Technical expertise/Digital preservation experts & $15(68.2 \%)$ & $6(27.3 \%)$ & $1(4.5 \%)$ & 0 & 0 \\
\hline Skilled trained staff & $11(50.0 \%)$ & $10(45.4 \%)$ & $1(4.5 \%)$ & 0 & 0 \\
\hline Knowledge of metadata systems & $12(54.5 \%)$ & $8(36.4 \%)$ & $1(4.5 \%)$ & $1(4.5 \%)$ & 0 \\
\hline Knowledge of preservation tools & $10(45.4 \%)$ & $11(50.0 \%)$ & $1(4.5 \%)$ & 0 & 0 \\
\hline
\end{tabular}

With regards to the factors enabling effective preservation of digital resources in academic libraries (Table 2), the results show that most academic institutions agreed that the following were important: management support (22; 100\%), adequately skilled staff, adequate training and effective leadership (all $21 ; 95.4 \%$ ), proper ICT infrastructure and sufficient budget $(20 ; 90.9 \%)$ and collaboration with other institutions $(20 ; 90.9 \%)$.

Table 2 Factors enabling the effective preservation of digital resources in academic libraries ( $N=27)$

\begin{tabular}{|c|c|c|c|c|c|}
\hline & Strongly Agree & Agree & Neutral & Disagree & $\begin{array}{l}\text { Strongly } \\
\text { Disagree }\end{array}$ \\
\hline Effective leadership & $15(68.2 \%)$ & $6(27.3 \%)$ & $1(4.5 \%)$ & 0 & 0 \\
\hline Proper ICT infrastructure & $12(54.5 \%)$ & $8(36.4 \%)$ & $2(9.1 \%)$ & 0 & 0 \\
\hline Adequate skilled staff & $13(59.1 \%)$ & $8(36.4 \%)$ & $1(4.5 \%)$ & 0 & 0 \\
\hline Adequate training & $11(50.0 \%)$ & $10(45.4 \%)$ & $1(4.5 \%)$ & 0 & 0 \\
\hline Management support & $14(63.6 \%)$ & $8(36.4 \%)$ & 0 & 0 & 0 \\
\hline Collaboration with other institutions & $10(45.4 \%)$ & $10(45.4 \%)$ & $2(9.1 \%)$ & 0 & 0 \\
\hline
\end{tabular}

These results align with the research article by the Council of Canadian Academies (2015) that documented the key factors that contribute to the success of memory institutions in the digital age. These include enactment of digital policies, participatory and collaborative culture, effective leadership in both institutional and national levels, human resource capabilities, management support, technical standards, managing copyright and intellectual property, and reallocation of resources (Council of Canadian Academies 2015). Figure 1 combines the overview of factors from theoretical models, the literature review and the survey results.

It is clear from Figure 1 that the various authors represent the same views on the factors contributing to digital preservation framework. The findings form theories and models, the literature review and survey results, seem all to agree that sustainable digital preservation is determined by factors such as the implementation of clear policies, procedures and strategies, good governance, collaboration, participatory partnerships, copyright and intellectual property rights, human and 
financial resources, education and training, technology infrastructure, technical expertise, raising awareness, commitment and willingness, prioritization of digital preservation initiatives and aligning them with the organisation's goals and mission.

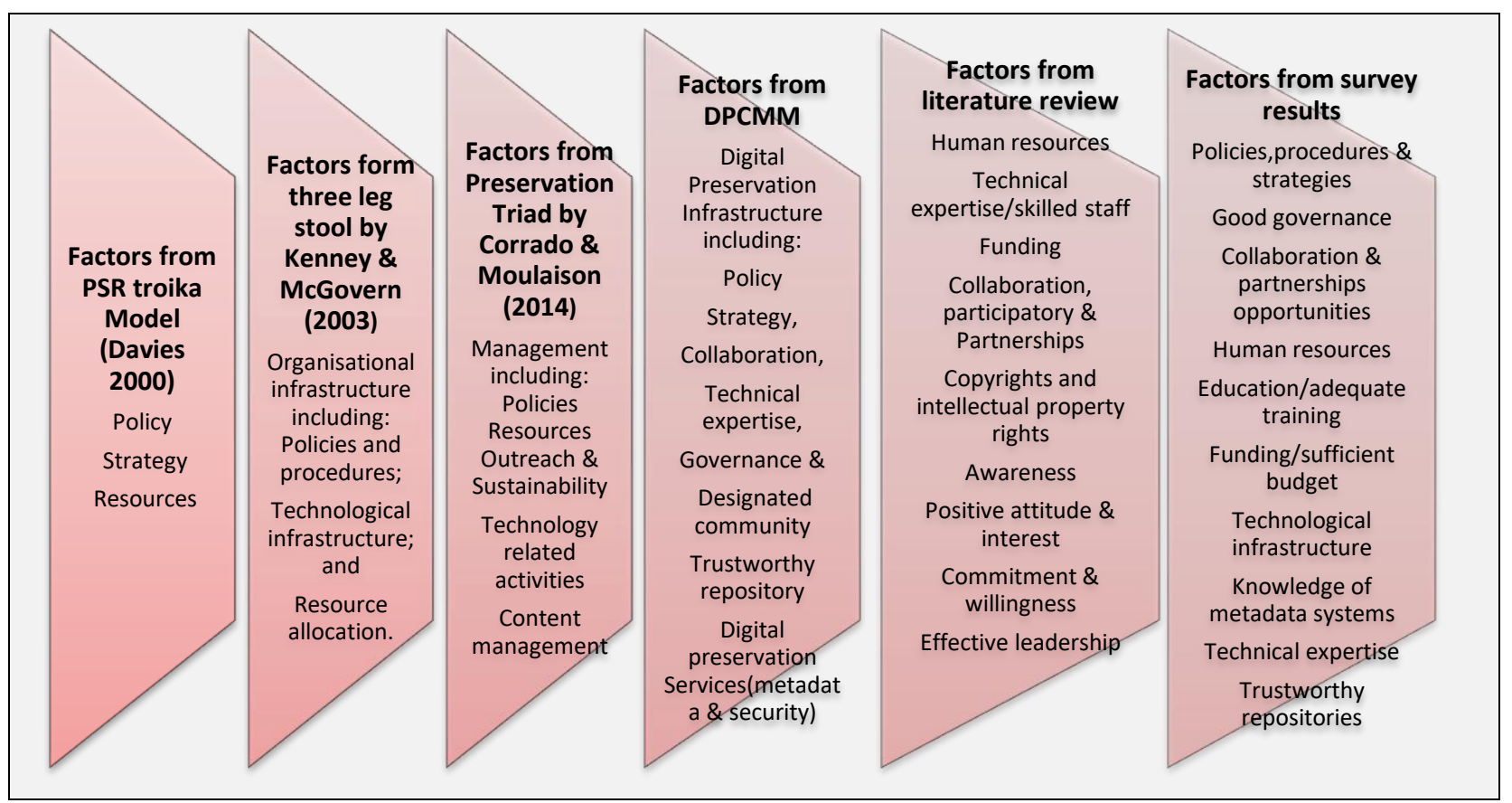

Figure 1 Factors contributing to digital preservation sustainability

\subsection{A conceptual integrated model of factors influencing digital preservation sustainability}

A conceptual integrated preservation model is proposed in this study to assist in the implementation of effective digital preservation within academic libraries in South Africa. The model was developed from survey findings, the literature review of previous studies and theoretical considerations based on digital preservation best practices. A conceptual integrated model is taken to represent the logical linkage of key selected components that could be used to examine and understand the preservation of digital resources in academic libraries which include: current digital preservation practices, digital preservation challenges, strategies for digital preservation, systems and tools used for digital preservation, and factors influencing digital preservation sustainability. Figure 2 shows a proposed conceptual integrated preservation model, summarised into three major areas, namely: management-related factors, resource-related factors and technology-related factors.

Several studies have been conducted but there have not been studies that are specifically targeted at identifying successful factors of digital preservation with a view to develop a conceptual integrated model for digital preservation applicable to academic libraries in South Africa This study was premised on testing other authors' theories and models such as the PSR troika model (Davies 2000), the Digital Preservation Triad (Corrado and Moulaison 2014) and the Digital Preservation Capability Maturity (DPCM) model (Carnegie Mellon University 1990).Therefore, reviewing all these theories and models was important and necessary in order to identify the key concepts or elements that can be used to ensure digital preservation sustainability and to further develop a conceptual integrated model for preservation of digital resources in academic libraries in South Africa. It is argued that all these factors are key to guiding digital preservation practices and are appropriate for implementing a sustainable digital preservation programme in academic libraries in South Africa. The proposed model was also mapped with the functional requirements of the OAIS reference model. Therefore, whereas the proposed conceptual model emphasises the development of policies, procedures, structures and systems to ensure the longevity of digital resources, the OAIS model helped to explain how the implementation of digital preservation programmes can be facilitated by creating and capturing their digital content as well as providing access to digital content. Technological obsolescence has also posed many challenges that hinder long-term preservation of digital information. The OAIS model has the capacity to overcome this challenge by reliably migrating information and providing long-term access to digital information.

\section{Conclusion and recommendations}

This paper was aimed at establishing factors that influence digital preservation sustainability in academic libraries in South Africa, with a view to proposing a model of digital preservation. The literature review revealed a growing awareness about digital preservation in South Africa through the support of national and international agencies with an increasing number of 
academic institutions making an effort to preserve their library materials through digitisation and implementation of institutional repositories. However, these efforts are being hampered by a limited or complete lack of human, financial and technological resources at the institutions with statutory responsibility for digital preservation. The PSR troika model (Davies 2000), Digital Preservation Triad (Corrado \& Moulaison 2014) and Digital Preservation Capability Maturity (DPCM) model (Carnegie Mellon University 1990) were found to be the most relevant models to validate the contributing factors. This paper revealed several factors enabling effective digital preservation and concludes that digital preservation sustainability may be influenced by factors such as good governance; participation and collaboration; knowledge of preservation software, tools and metadata systems; an increase in education and training among staff members; increased awareness, commitment and outreach in preservation activities; technical expertise; and knowledge of copyright and intellectual property rights.

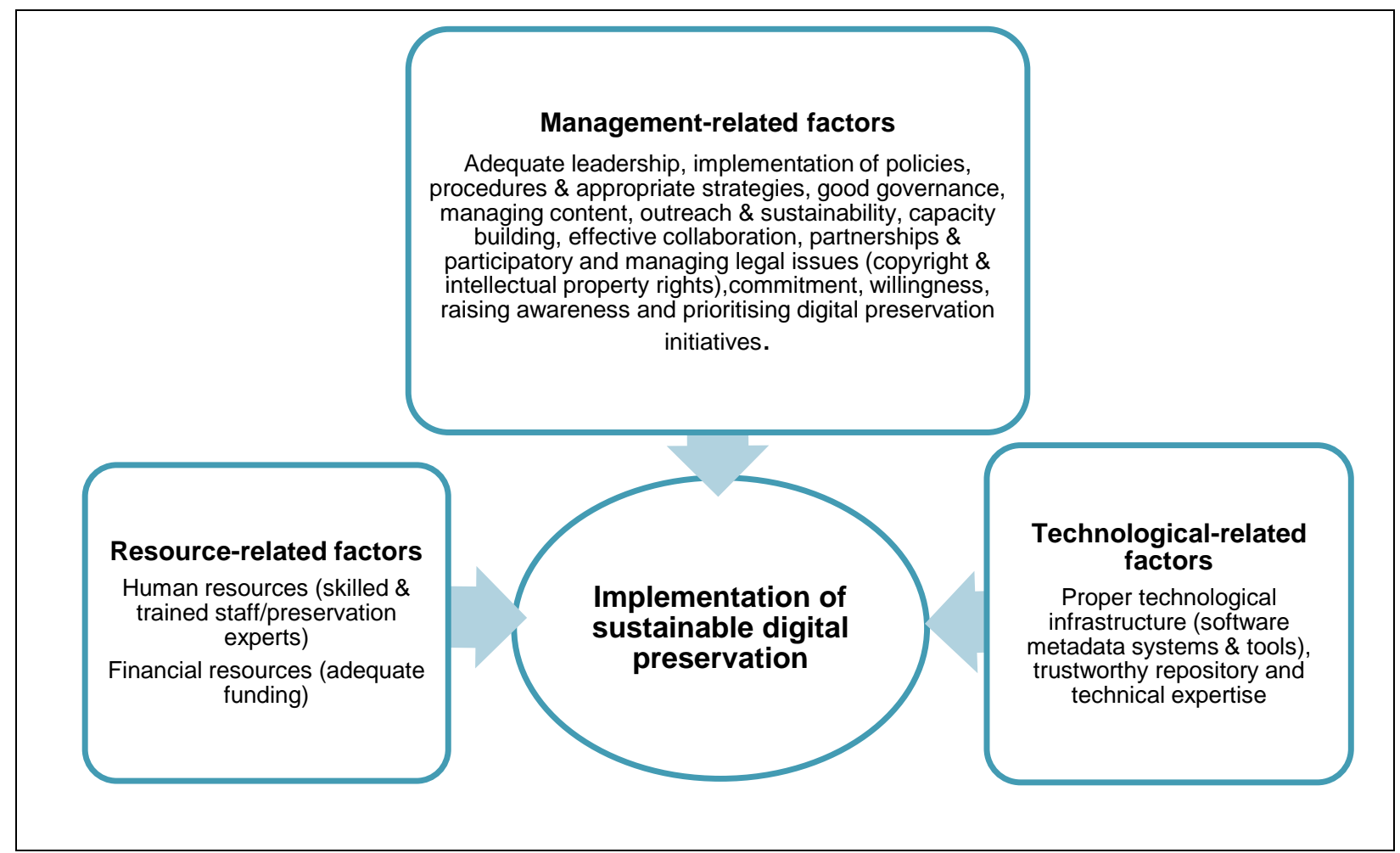

Figure 2 A proposed conceptual integrated preservation model

In some instances, institutions were not fully involved in collaborations with other institutions, therefore, this research recommends that institutions build partnerships with other institutions (nationally and internationally). In Canada, for example, aboriginal communities are collaborating with museums to create culturally sensitive content management systems to support access to their cultural heritage and facilitate self-representation (Council of Canadian Academies 2015). By collaborating with other institutions, they would be exposed to new ideas, strategies and tools and be able to acquire knowledge and skills needed to preserve and manage their digital resources successfully. Management in these institutions need also benchmark with other institutions in terms of good governance, implementation of policies and building proper infrastructures through collaborative and partnership efforts. This study therefore recommends a multi-pronged approach to digital preservation including the enactment of preservation policies, proper allocation of resources, more collaboration and improved technology infrastructure to address software and hardware obsolescence

\section{References}

American Library Association. 2007. Definitions of digital preservation. [Online]. http://www.ala.org/alcts/resources/preserv/defdigpres0408.

Anyaoku, E.N, Echedom, A.U.N. and Baro, E.E. 2019.Digital preservation practices in university libraries: an investigation of institutional repositories in Africa. Digital Library Perspectives, 35(1): 41-64.

Beagrie, N., Semple, N., Williams, P. and Wright, R. 2008. Digital preservation policies study: part 1: final report October 2008. Bristol: HEFCE [Online].

http://citeseerx.ist.psu.edu/viewdoc/download?doi=10.1.1.214.9056\&rep=rep1\&type=pdf (4 October 2013).

Bishoff, L. and Smith, C. 2015. Managing digital collections survey results. D-Lib Magazine, 21(3): 1-11.

Carnegie Mellon University. 1990. The System Security Engineering: Capability Maturity Model (SSE-CMM), Version 2. (Unpublished). 
Consultative Committee for Space Data Systems. 2002. Reference model for an open archival information system (OAIS). Washington, DC.: CCSDS.

Copyright Act 98 of 1978. 1978. Pretoria: Government Printers.

Copyright Amendment Bill, No. 13B of 2017. 2017. Pretoria: Government Printers.

Corrado, E.M. and Moulaison, H.L. 2014. Digital preservation for libraries, archives, and museums. Lanham, MD: Rowman \& Littlefield.

Council of Canadian Academies. 2015. Leading in the digital world: opportunities for Canada's memory institutions. The expert panel on memory institutions and the digital revolution. Ottawa, Canada: Council of Canadian Academies.

Das T.K., Sharma, A.K. and Gurey, P. 2009. Digitization, strategies and issues of digital preservation: an insight view to Visva-Bharati Library. Proceedings of the $7^{\text {th }}$ international Convention on Automation of Libraries in Education and Research (CALIBER). 25- 27 February 2009. Ahmedabad: Information and Library Network Centre. 35-40

Davies, W. 2000. Understanding strategy. Strategy \& Leadership, 28(5): 25-30.

Dollar, C.M. and Ashley, L.J. 2014. Assessing digital preservation capability using a maturity model process improvement approach. [Online]. https://static1.squarespace.com/static/52ebbb45e4b06f07f8bb62bd/t/53559340e4b058b6b2212d98/1398117184845/ DPCMM+White+Paper_Revised+April+2014.pdf (24 June 2020).

Dressler, V.A. 2017. The state of affairs with digital preservation at ARL member libraries: a survey and analysis of policy. Digital Library Perspectives, 33(2): 137-155.

Electronic Resource Preservation and Access Network (ERPANET). 2003. Digital Preservation Policy Tool. [Online]. https://www.erpanet.org/guidance/docs/ERPANETPolicyTool.pdf (11 January 2014).

Gbaje, E. and Zakari, M. 2013. Digital preservation policy in National Information Centers in Nigeria. The Electronic Library, 31(4): 483-492.

Hedstrom, M. 1997. Digital preservation: a time bomb for digital libraries. Computers and the Humanities, 31: $189-202$.

Hockx-Yu, H. 2006. Digital preservation in the context of institutional repositories. Electronic Library and Information Systems, 40(3): 232-243.

Imenda, S. 2014. Is there a conceptual difference between theoretical and conceptual frameworks? Sosyal Bilimler Dergisi/Journal of Social Sciences, 38(2): 185-195.

Institute of Museum and Library Services. 2001. New directives, new directions: documenting outcomes in IMLS grants to libraries and museums. Washington, DC: Institute of Museum and Library Services.

International Organisation for Standardisation (ISO). 2003. ISO 14721:2012 Space data and information transfer systems - Open archival information system (OAIS) - Reference model. Geneva: ISO.

Kanyengo, C.W. 2006. Managing digital information resources in Africa: preserving the integrity of scholarship. The International Information and Library Review, 41(1): 34-43.

Khan, S.A. and Bhatti, R. 2017. Digital competencies for developing and managing digital libraries: an investigation from university librarians in Pakistan. The Electronic Library, 35(3): 133-142.

Lampert, C. and Vaughan, J. 2009. Success factors and strategic planning: rebuilding an academic library digitization program. Information Technology and Libraries, 28(3): 116-138.

Lewis, D.W. 2007. A strategy for academic libraries in the first quarter of the $21^{\text {st }}$ century. College \& Research Libraries, 68(5): 418-434.

Luyombya, D. 2010. Framework for effective digital records management in Uganda. PhD Thesis. University of London.

Mannheimer, S. and Cote, C. 2017. Cultivate, assess, advocate, implement, and sustain: a five-point plan for successful digital preservation collaborations. Digital Library Perspectives, 33(2): 100-116.

Masenya, T.M. 2018. A framework for preservation of digital resources in academic libraries in South Africa. PhD Thesis. University of South Africa.

McGovern, Y.N. and McKay, C.A. 2008. Leveraging short-term opportunities to address long-term obligation: a perspective on institutional repositories and preservation programs. Library Trends, 57(2): 262-279.

Muir, A. 2004. Digital preservation, awareness, responsibilities and rights issues. Journal of Information Science, 30(1): 73-92.

NASA-NSSDC. 2010. Data collection details: Viking 2 Lander Raw image EDRs in CD-ROM. National Space Data Center: United State of America.

Ngulube, P. 2004. A double-edged sword: challenges and opportunities offered by the digital age to the African Information Society. In ProLISSA 2004 : progress in library and information science in southern Africa : proceedings of the third biennial DISSAnet Conference. T. Bothma \& A. Kaniki, Eds. 28-29 October 2004. Pretoria: Infuse.

Ngulube, P. 2012. "Ghosts in our machines": Preserving public digital information for the sustenance of electronic government in sub-Saharan Africa. Mousaion: South African Journal of Information Studies, 30(2): 127-135.

Ngulube, P. 2019. Handbook of research on advocacy, promotion and public programming for memory institutions. Hershey, PA: IGI-Global.

Noonan, D. 2014. Digital preservation policy framework: a case study. EDUCAUSE Review, 49(4): 1-23.

Parsons, W. 1995. Public policy : an introduction to the theory and practice of policy analysis. Cheltenham: Edward Elgar. 
Quisbert, H. 2008. On long-term digital preservation information system: A framework and characteristics for development. Department of Business Administration and Social Science of Computer \& Systems Science: Lulea University of Technology.

Raju, J. 2014. Knowledge and skills for the digital era academic library. The Journal of Academic Librarianship, 40: 163170.

Research Libraries Group and OCLC. 2002. Trusted digital repositories: attributes and responsibilities. Mountain View, CA: Research Libraries Group.

Rosenthal, D.S.H., Robertson, T., Lipkis, T., Reich, V. and Morabito, S. 2005. Requirements for digital preservation systems: a bottom-up approach. D-Lib Magazine, 11(11). [Online]. http://www.dlib.org/dlib/november05/rosenthal/11 rosenthal.html.

Ryan, D. 2010. Aluka: digitization from Maputo to Timbuktu. OCLC Systems \& Services: International digital library perspectives, 26(1): 29-38.

Sigauke, D.T. and Nengomasha, C.T. 2012. Challenges and prospects facing the digitization of historical records for their preservation with national archives of Zimbabwe. Paper presented at the $2^{\text {nd }}$ International Conference in African Digital Libraries and Archives. 17-18 November 2011. Johannesburg, South Africa

Simpson, D. 2004. Risk of loss of digital data and the reasons it occurs: case studies and analysis. Glasgow: Digital Preservation Coalition. [Online]. https://www.dpconline.org/docs/miscellaneous/members/117-risk-of-loss-of-digitaldata/file.

Styblinski, M.A. and Huang, M. 2006. Drift reliability optimization in IC design: generalized formulation and practical examples. IEEE Transactions on Computer-Aided Design of Integrated Circuits and Systems, 12(8).

Swan, A. 2012. Policy guidelines for the development and promotion of open access. Paris: UNESCO.

Van Deventer, M. and Pienaar, H. 2008. South African repositories: bridging knowledge divides. Ariadne. 55. [Online]. http://www.ariadne.ac.uk/issue55/vandeventer-pienaar (30 April 2008).

Wright, R. 2012. Preserving moving pictures and sound. Glasgow: Digital Preservation Coalition. [Online]. https://www.dpconline.org/docs/technology-watch-reports/753-dpctw12-01-pdf/file.

Zlotin, B. and Zusman A. 2005. The concept of resources in TRIZ: past, present and future. Southfield, Michigan: Ideation International. 